\title{
Efeito de níveis crescentes de uréia na dieta de vacas leiteiras sobre a composição e rendimento de fabricação de queijos minas frescal
}

\author{
Adriana Augusto AQUINO ${ }^{1}$ \\ Kleber da Cunha PEIXOTO \\ JUNIOR ${ }^{2}$ \\ Mirna Lúcia GIGANTE ${ }^{3}$ \\ Francisco Palma RENNÓ ${ }^{4}$ \\ Luis Felipe PRADA e SILVA ${ }^{4}$ \\ Marcos Veiga dos SANTOS ${ }^{4}$
}

Correspondência para:

mveiga@usp.br

Recebido para publicação: 18/06/2007 Aprovado para publicação: 30/04/2009

\author{
1 - Doutoranda em Zootecnia pela Universidade Federal de Lavras, Lavras- MG \\ 2 - Universidade Metodista de São Paulo, São Bernardo do Campo-SP \\ 3 - Faculdade de Engenharia de Alimentos da Universidade Estadual de Campinas, \\ Campinas-SP \\ 4 - Departamento de Nutrição e Produção Animal da Faculdade de Medicina \\ Veterinária e Zootecnia da Universidade de São Paulo, Pirassununga-SP
}

\section{Resumo}

O objetivo do trabalho foi avaliar a substituição do farelo de soja por níveis crescentes de uréia na dieta de vacas leiteiras e os seus efeitos sobre a composição e o rendimento de fabricação de queijo Minas Frescal. Para a fabricação dos queijos, foram utilizados $15 \mathrm{~kg}$ de leite, provenientes de nove vacas Holandesas em lactação, distribuídas em três quadrados latinos 3x3. Foram utilizadas três dietas: A) controle, formulada para suprir $100 \%$ das exigências de proteína bruta, proteína degradável no rúmen (PDR) e proteína não degradável no rúmen (PNDR), utilizando farelo de soja como principal fonte protéica; B) com a inclusão de $0,75 \%$ de uréia, em substituição parcial ao farelo de soja, e C) com inclusão de 1,5\% de uréia, em substituição parcial ao farelo de soja. Todas as dietas foram isoenergéticas $(1,53 \mathrm{Mcal} / \mathrm{kg}$ de energia líquida de lactação) e isonitrogenadas (16\% de PB) e utilizaram cana-de-açúcar como volumoso. Quando analisados por regressão polinomial simples, os resultados da composição e da fração nitrogenada do leite pasteurizado não foram influenciados pelo nível de uréia na dieta, o mesmo ocorrendo com a composição $(\mathrm{pH}$, umidade, gordura, matéria mineral, cloreto de sódio, proteína bruta, nitrogênio solúvel em pH 4,6 e em TCA 12\%) e o rendimento de fabricação dos queijos. Com base nos resultados deste estudo, concluise que o uso de até $1,5 \%$ de uréia na alimentação de vacas em lactação não alterou a composição do leite pasteurizado, bem como a composição e o rendimento de fabricação de queijo Minas Frescal.

\section{Introdução}

O uso de nitrogênio não-protéico (NNP) como fonte de proteína degradável no rúmen é uma estratégia nutricional bastante comum no Brasil e objetiva a redução dos custos da proteína da dieta, sem alterar a produção e a proteína do leite. Contudo, a utilização de NNP na dieta pode alterar a composição da proteína do leite, influenciando o processamento industrial da matéria-prima, já que os teores de proteína verdadeira e da caseína têm influência direta sobre a fabricação do queijo. ${ }^{1,2}$
Palavras-chaves: Nitrogênio não protéico. Composição do leite. Qualidade do queijo. Nutrição.
A hipótese do presente estudo é de que a substituição de farelo de soja por uréia como fonte de NNP para vacas leiteiras em lactação pode alterar a síntese de proteína do leite e as sua frações protéicas, resultando em modificações na composição e qualidade do queijo Minas Frescal fabricados a partir dessa matéria-prima. Dessa forma, o objetivo do presente estudo foi avaliar a substituição de farelo de soja por níveis crescentes de uréia $(0,0,75$ e 1,5\% da matéria seca, MS) na dieta de vacas leiteiras e os seus efeitos sobre a composição e a fração protéica do leite pasteurizado, e a 
composição e o rendimento de fabricação do queijo Minas Frescal.

\section{Material e Método}

Foi utilizado o delineamento em quadrado latino $3 \times 3$, com três tratamentos, três períodos experimentais e três quadrados. Foi adotado um período de adaptação de 18 dias e realização de coleta de amostras de leite nos últimos três dias de cada período, totalizando 21 dias por período. Foram utilizadas nove vacas adultas ( $>2^{\mathrm{a}}$ lactação) da raça Holandesa, do $2^{\circ}$ ao $7^{\circ}$ mês de lactação com peso vivo médio de $560 \mathrm{~kg} \pm 30 \mathrm{~kg}$ e hígidas.

Os tratamentos foram compostos por três dietas, sendo a dieta controle formulada para suprir $100 \%$ das exigências de proteína bruta, proteína degradável no rúmen (PDR) e proteína não degradável no rúmen (PNDR) ${ }^{3}$, utilizando farelo de soja como principal fonte protéica e cana de açúcar como volumoso. As outras duas dietas, com 0,75 ou $1,5 \%$ de uréia em substituição ao farelo de soja, foram formuladas para atender 100\% das exigências de $\mathrm{PB}$, com manutenção do nível de PB igual ao da dieta controle e cana de açúcar como volumoso (Tabela 1). As dietas foram

Tabela 1 - Proporções de ingredientes e composição bromatológica das dietas experimentais, segundo nível de inclusão na matéria seca (MS)

\begin{tabular}{|c|c|c|c|}
\hline \multirow[t]{2}{*}{ Ingredientes (\% da MS) } & \multicolumn{3}{|c|}{ \% de inclusão de uréia na MS } \\
\hline & 0 & 0,75 & 1,5 \\
\hline Cana de açúcar & 43,35 & 41,42 & 39,50 \\
\hline Milho grão, moído & 28,12 & 34,72 & 41,33 \\
\hline Farelo de Soja & 25,70 & 20,17 & 14,61 \\
\hline Uréia $45 \% \mathrm{~N}$ & 0 & 0,75 & 1,50 \\
\hline Fosfato bicálcico & 0,39 & 0,50 & 0,62 \\
\hline Calcário calcítico & 0,94 & 0,94 & 0,94 \\
\hline Sal branco & 0,50 & 0,50 & 0,50 \\
\hline Mistura mineral $^{1}$ & 1,00 & 1,00 & 1,00 \\
\hline Composição da dieta (\% da MS) & 100 & 100 & 100 \\
\hline Matéria Seca ${ }^{2}$ & 61,82 & 63,85 & 64,03 \\
\hline Proteína Bruta & 16,17 & 16,33 & 16,21 \\
\hline Proteína degradável ${ }^{3}$ & 66,60 & 69,63 & 72,65 \\
\hline Proteína não degradável ${ }^{3}$ & 33,40 & 30,37 & 27,35 \\
\hline Fibra em Detergente Neutro (\%) & 31,76 & 30,34 & 29,56 \\
\hline Fibra em Detergente Ácido (\%) & 21,80 & 20,48 & 19,41 \\
\hline ExtratoEtéreo (\%) & 5,22 & 5,03 & 5,13 \\
\hline Cálcio (\%) & 0,72 & 0,72 & 0,80 \\
\hline Fósforo (\%) & 0,46 & 0,44 & 0,45 \\
\hline Energia líquida para lactação (Mcal $/ \mathrm{kg})^{4}$ & 1,53 & 1,53 & 1,53 \\
\hline Matéria Mineral (\%) & 4,91 & 4,70 & 4,30 \\
\hline
\end{tabular}

Composição por kg de mistura mineral: $180 \mathrm{~g} \mathrm{Ca}, 90 \mathrm{~g} \mathrm{P}, 20 \mathrm{~g} \mathrm{Mg}, 20 \mathrm{~g} \mathrm{~S}, 100 \mathrm{~g} \mathrm{Na}, 3.000 \mathrm{mg}$ $\mathrm{Zn}, 1.000 \mathrm{mg} \mathrm{Cu}, 1.250 \mathrm{mg} \mathrm{Mn}, 2.000 \mathrm{mg} \mathrm{Fe}, 200 \mathrm{mg} \mathrm{Co}, 90 \mathrm{mg} \mathrm{I}, 36 \mathrm{mg} \mathrm{Se}, 900 \mathrm{mg} \mathrm{F}$ (máximo). ${ }^{2 \%}$ da matéria natural ${ }^{3} \mathrm{Em} \%$ da $\mathrm{PB},{ }^{4}$ Estimado segundo NRC (2001) 
isonitrogenadas, contendo $16 \%$ de proteína bruta na MS, e isoenergéticas, com 1,53 $\mathrm{Mcal} / \mathrm{kg}$ de energia líquida para lactação, sendo fornecidas na forma de mistura completa, 2 vezes ao dia (após as ordenhas da manhã e da tarde), de forma a permitir $5 \%$ de sobras. Durante os quatro últimos dias de cada um dos três períodos experimentais foi realizada a pesagem das sobras, coleta das amostras das dietas e coleta das amostras de leite. Os animais foram pesados no início e no final de cada período experimental.

Durante os três últimos dias do período experimental, foram coletados diária e individualmente da produção das vacas, quinze quilos de leite para a fabricação de cada queijo Minas Frescal, seguindo a recomendação de Oliveira ${ }^{2}$. Amostras de leite pasteurizado foram coletadas e analisadas quanto a sua composição (gordura, lactose, sólidos totais) por absorção infravermelha com o uso do equipamento Bentley 2000 (Bentley Instruments Inc. Chasca, MN, USA), nitrogênio total ${ }^{4}$, utilizando-se 6,38 como fator de conversão para proteína bruta, nitrogênio nãoprotéico $^{5}$, nitrogênio não caseinoso ${ }^{5}$ e uréia pelo método colorimétrico-enzimático no equipamento Bentley Chemspec 150 (Bentley
Instruments Inc. Chasca, MN, USA).

Foram coletadas amostras dos queijos, as quais foram analisadas quanto ao: $\mathrm{pH}$, matéria seca ${ }^{6}$, umidade (100-EST), gordura pelo método de Gerber ${ }^{6}$, cinzas por incineração ${ }^{4}$, sal pelo método de Volhard ${ }^{6}$ nitrogênio total pelo método de Kjeldahl ${ }^{4}$, nitrogênio solúvel em pH 4,6 e em TCA $12 \%{ }^{4}$. O soro do queijo foi analisado quanto à: acidez titulável, gordura, pelo método de Monjonnier, nitrogênio total, nitrogênio solúvel em pH 4,6 e em TCA 12\% ${ }^{4}$. Foram calculados o rendimento bruto $^{7}$ o rendimento ajustado ${ }^{7}$ e a recuperação de proteína e gordura ${ }^{7}$. Os resultados submetidos à regressão polinomial simples, utilizando como fonte de variação os efeitos de tratamento, animal (dentro de quadrado), período e quadrado ${ }^{8}$.

\section{Resultados e Discussão}

A composição do leite pasteurizado e da fração nitrogenada não foi influenciada ( $P>0,05)$ pelos níveis crescentes de uréia adicionados nas dietas (Tabela 2). Os resultados obtidos para o teor de proteína bruta $(\mathrm{PB})$ do leite pasteurizado variaram de 3,45 a 3,66\% e são similares aos descritos por Carmo et al. ${ }^{9}$, os quais relataram que a adição

Tabela 2 - Efeito o nível de inclusão de uréia na dieta (\% MS) sobre a composição do leite pasteurizado

\begin{tabular}{lccccccc}
\hline & & \multicolumn{3}{c}{ Níveis de inclusão de uréia na dieta (\% MS) } & & \multicolumn{3}{c}{ P } \\
Variável & $\mathbf{N}$ & $\mathbf{0}$ & $\mathbf{0 , 7 5}$ & $\mathbf{1 , 5}$ & $\mathbf{C V}$ & $\mathbf{L}$ & $\mathbf{D}$ \\
\hline PB (\%) & 26 & 3,66 & 3,46 & 3,45 & 11,37 & 0,101 & 0,445 \\
NNP (\% PB) & 26 & 7,92 & 7,80 & 8,10 & 12,94 & 0,421 & 0,445 \\
PV (\%) & 26 & 3,36 & 3,19 & 3,17 & 12,82 & 0,145 & 0,518 \\
PV (\%PB) & 26 & 91,94 & 91,97 & 91,84 & 1,77 & 0,878 & 0,892 \\
Caseína (\%) & 26 & 2,89 & 2,68 & 2,69 & 14,00 & 0,146 & 0,429 \\
Caseína (\%PB) & 26 & 78,72 & 77,45 & 77,68 & 4,09 & 0,492 & 0,526 \\
Uréia (mg/d1) & 25 & 18,31 & 17,79 & 18,55 & 18,97 & 0,675 & 0,929 \\
Caseína/PV & 26 & 0,86 & 0,84 & 0,85 & 3,57 & 0,448 & 0,395 \\
Gordura(\%) & 25 & 2,80 & 2,70 & 2,63 & 1,77 & 0,111 & 0,602 \\
Lactose(\%) & 25 & 4,75 & 4,70 & 4,70 & 4,06 & 0,422 & 0,560 \\
EST(\%) & 25 & 11,87 & 11,70 & 11,61 & 5,12 & 0,059 & 0,368 \\
ESD(\%) & 25 & 9,06 & 9,00 & 8,98 & 5,45 & 0,436 & 0,453 \\
\hline
\end{tabular}

$\mathrm{PB}=$ proteina bruta; $\mathrm{NNP}=$ nitrogênio não protéico; $\mathrm{NNC}=$ nitrogênio não caseinoso; $\mathrm{PV}=$ proteína verdadeira; $\mathrm{PV}(\% \mathrm{~PB})=$ proteína verdadeira como porcentagem da proteina bruta, Caseina $\mathrm{PV}=$ relação caseina-proteina verdadeira; $\mathrm{EST}=$ extrato seco total; $\mathrm{ESD}=$ extrato seco desengordura do; $\mathrm{CV}=$ Coeficiente de Variação; $\mathrm{L}=$ probabilidade para efeito linear; $\mathrm{D}=$ probabilida de para efeito desvio 
de uréia e fontes de proteína degradável no rúmen não altera o teor deste componente. No entanto, Oliveira et al. ${ }^{10}$, e Silva et al. ${ }^{11}$, mostraram diminuição dos teores de proteína bruta no leite de vacas suplementadas com fontes de NNP, o que pode estar relacionado com o menor consumo de matéria seca registrado nesses estudos. Os resultados obtidos no presente estudo sugerem que a adição de até 1,5\% de uréia na dieta de vacas no meio da lactação não altera a capacidade de produção de proteína microbiana no rúmen, além de atender as necessidades de proteína metabolizável. O uso do NNP em substituição a proteína verdadeira, aliada ao fornecimento de uma fonte de energia prontamente disponível, como a proveniente da cana de açúcar, parece ser viável para animais com produção de leite de até $25 \mathrm{~kg}$.

Da mesma forma, não houve efeito das dietas experimentais sobre a composição da fração nitrogenada do leite, o que contrasta com os resultados descritos por Reynal e Broderick ${ }^{12}$ que observaram efeito linear dos níveis de proteína degradável no rúmen sobre a porcentagem de proteína verdadeira do leite, indicando que a diminuição da porcentagem de proteína degradável no rúmen resulta em aumento na concentração na proteína verdadeira do leite. No presente trabalho, a substituição do farelo de soja por uréia resultou em dietas com $10,65 \%, 11,14 \%$ e $11,62 \%$ de PDR para os tratamentos com $0 \%, 0,75 \%$, e 1,5\% de inclusão de uréia na dieta, respectivamente. Com esses níveis de PDR, não foi possível observar diferença entre os tratamentos na concentração de proteína verdadeira.

Neste estudo, as concentrações de caseína também não foram influenciadas pelos níveis crescentes de uréia na dieta. Desta forma, a substituição parcial do farelo de soja pela uréia, em até 1,5\%, não limitou a capacidade de produção desta proteína na glândula mamária. Bateman et al. ${ }^{13}$ que compararam o uso da uréia e do farelo de soja com fontes de proteína não degradável associada a aminoácidos protegidos, em dietas utilizando feno de alfafa como volumoso, também obtiveram resultados similares. Além disso, como as concentrações e os teores de proteína total, proteína verdadeira e caseína não foram influenciados pelas dietas, e as relações proteína verdadeira/proteína total e caseína/proteína verdadeira, igualmente, não foram alteradas. Resultados semelhantes foram verificados por Coulon et al. ${ }^{14}$, que observou que a diferença do uso fontes de nitrogênio aumenta a concentração de proteína total, mas não altera a relação caseína: proteína.

Os queijos, assim como os soros produzidos também não sofreram diferenças em sua composição em função das dietas. Os resultados para rendimento e cifras de transição de gordura e proteína estão demonstrados nas tabelas 3 e 4, respectivamente. Os resultados obtidos para $\mathrm{pH}$, umidade, gordura, matéria mineral, $\mathrm{NaCl}$, proteína bruta, nitrogênio solúvel em pH 4,6 e nitrogênio solúvel em TCA $12 \%$, não sofreram influência dos níveis crescentes de uréia adicionados à dieta. Não foram encontrados outros estudos avaliando o efeito da adição de fontes de NNP na alimentação animal, como a uréia, e que avaliaram a composição e o rendimento de fabricação do queijo Minas Frescal.

Neste estudo, a inclusão de uréia na dieta das vacas em lactação, até o limite de $1,5 \%$ da MS, não afetou a composição do leite pasteurizado utilizado e as cifras de transição para gordura e proteína, o que explicaria a ausência de efeitos sobre a composição dos queijos. Os valores de $\mathrm{pH}(6,18,6,10$ e 6,35 , para os tratamentos $0,0,75$ e $1,5 \%$ de inclusão de uréia, respectivamente), foram determinados 24 horas após a produção dos queijos, e são similares aos obtidos por Cunha et al. ${ }^{15}$.

O teor de umidade do queijo Minas Frescal tradicional varia de 55 a $60 \% \%^{2}$, e os queijos obtidos no processamento apresentaram umidade próxima a esta 
Tabela 3 - Efeito o nível de inclusão de uréia na dieta (\% MS) sobre a composição físico-química do queijo e soro

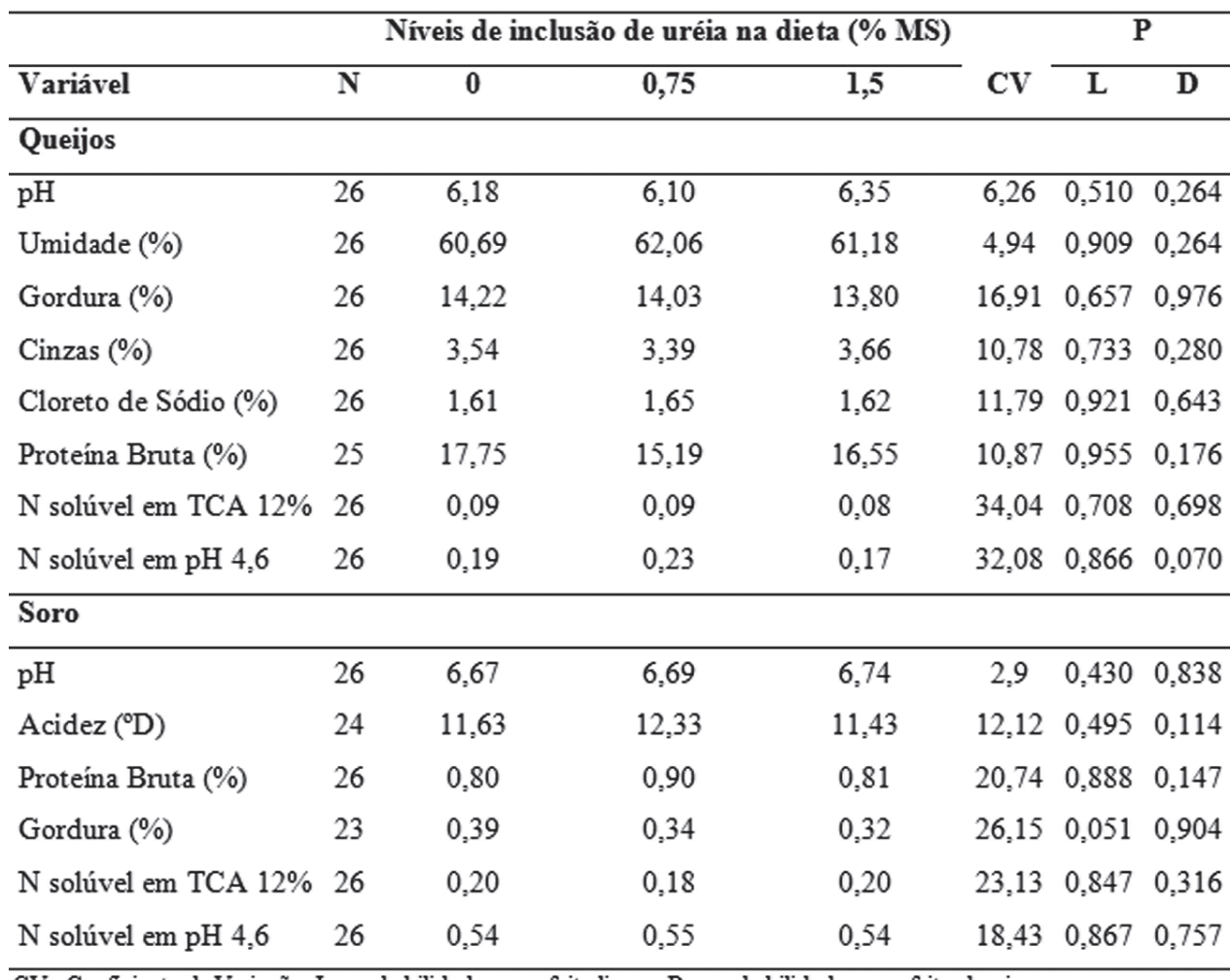

$\mathrm{CV}=$ Coeficiente de Variação; $\mathrm{L}=$ probabilidade para efeito linear; $\mathrm{D}=$ probabilida de para efeito desvio

Tabela 4 - Efeito o nível de inclusão de uréia na dieta (\% MS) sobre o rendimento ajustado e as cifras de transição de gordura e proteína de fabricação do queijo Minas Frescal

\begin{tabular}{|c|c|c|c|c|c|c|c|}
\hline \multirow[b]{3}{*}{ Variável } & \multirow[b]{3}{*}{$\mathbf{N}$} & \multicolumn{4}{|c|}{ Níveis de inclusão de uréia na dieta (\% } & & \\
\hline & & & MS) & & \multirow[b]{2}{*}{$\mathrm{CV}$} & \multicolumn{2}{|c|}{$\mathbf{P}$} \\
\hline & & $\mathbf{0}$ & 0,75 & 1,5 & & $\mathbf{L}$ & $\mathbf{D}$ \\
\hline Raj (\%) & 26 & 17,14 & 16,44 & 16,28 & 13,67 & 0,432 & 0,690 \\
\hline Recuperação de Gordura (\%) & 23 & 88,36 & 89,92 & 88,64 & 3,48 & 0,920 & 0,367 \\
\hline Recuperação de Proteína Total (\%) & 26 & 81,52 & 78,42 & 80,42 & 4,43 & 0,594 & 0,096 \\
\hline
\end{tabular}

Raj= Rendimento ajustado, CV= Coeficiente de Variação; $\mathrm{L}=$ probabilidade para efeito linear; $\mathrm{D}=$ probabilida de para efeito desvio

faixa de variação. Quanto ao teor de gordura, valores mais baixos foram encontrados, provavelmente devido à utilização de leite com níveis mais baixos deste componente (Tabela 3). No tocante ao rendimento de fabricação dos queijos, a ausência de diferenças entre a concentração de proteína verdadeira e, especialmente de caseína na matéria-prima utilizada, explica a ausência de efeito da inclusão de uréia na dieta sobre o rendimento bruto, já que segundo Emmons, Dubé e Modler ${ }^{1}$, essa é a principal responsável pelo rendimento de fabricação. Como a composição dos queijos também não sofreu diferenças significativas quanto à umidade e sal, o rendimento ajustado não sofreu efeito em função das dietas utilizadas.

O uso de uréia é uma estratégia nutricional para vacas leiteiras amplamente utilizada no Brasil com a finalidade de reduzir custos de produção. Contudo, são escassas as informações em relação às suas influências sobre a qualidade do leite e importância econômica para a produção 
de derivados lácteos. Assim, nas condições experimentais do presente estudo, conclui-se que a utilização de até $1,5 \%$ de uréia na alimentação de vacas no meio de lactação não alterou a composição centesimal e a fração nitrogenada do leite pasteurizado, assim como a composição e o rendimento de fabricação de queijo Minas Frescal.

\section{Agradecimentos}

Os autores agradecem o auxílio financeiro da FAPESP e o apoio técnico de Lucinéia Mestieri e José Franchini Garcia Moreno.

\section{Effect of increasing level of dietary urea in diets for dairy cows on composition and yield of Minas Frescal cheese}

\section{Abstract}

The aim of this study was to evaluate the substitution of soybean meal for increasing levels of dietary urea on the composition and yield of Minas cheese. For each cheese making process, $15 \mathrm{~kg}$ of milk were collected from nine lactating Holstein cows that were arranged in 3 Latin squares. Three diets with sugar cane as roughage were fed for cows and consisted of: A) control diet formulated to provide 100\% of the requirements of crude protein $(\mathrm{CP})$, rumen undegradable protein (RUP) and rumen degradable protein (RDP), using soybean meal; B) urea inclusion at $0.75 \%$ of dry matter in substitution for soybean meal crude protein equivalent; C) urea inclusion at $1.5 \%$ of dry matter in substitution for soybean meal crude protein equivalent. Energy and protein levels of rations comply with NRC (2001), and were isoenergetic and isonitrogenous. When the data were analyzed by simple polynomial regression, no effect of treatments were observed on pasteurized milk composition and milk nitrogen fractions, as well as for cheese composition $(\mathrm{pH}$, moisture, fat,ash, sodium cloride, crude protein, soluble nitrogen in $\mathrm{pH} \mathrm{4,6}$ and in TCA $12 \%$ ) and cheese yield. Based on the results of this study, it can be concluded that the addition of urea up to $1.5 \%$ in dry matter basis in substitution for soybean meal in the diet of Holstein cows did not alter cheese composition and yield.

\section{Referências}

1 EMMONS, D. B.; DUBÉ, C.; MODLER, H. W. Transfer of protein from milk to cheese. Journal of Dairy Science, v. 86, n. 2, p. 469-485, 2003.

2 OLIVEIRA, J. S. Queijo: fundamentos tecnológicos. 2 ed. São Paulo: Ícone, 1986. 147 p.

3 NATIONAL RESEARCH COUNCIL. Nutrient requirements of dairy cattle. Washington: National Academy of Science, National Academy Press, 2001. $381 \mathrm{p}$.

4 ASSOCIATION OF OFFICIAL ANALYTICAL CHEMISTS. Official methods of analysis. 16. ed. Washington: Arlington, 1995. 1141 p.

5 ASSOCIATION OF OFFICIAL ANALYTICAL CHEMISTS. Official methods of analysis. $11 \mathrm{ed}$
Key words:

Non-protein nitrogen. Milk composition. Cheese yield. Nutrition.
Washington: Arlington, 1990. 1050 p.

6 RICHARDSON, G. H. Standard methods for examination of dairy products. Washington: American Public Health Association, 1985. 412 p.

7 LUCEY, J.; KELLY, J. Cheese yield. Journal of the Society of Dairy Technology, v. 47, n. 1, p. 1-14, 1994.

8 STATISTICAL ANALISYS SYSTEM. SAS user's guide: statistics. North Caroline: SAS, 1996. 842 p.

9 CARMO, C. A.; SANTOS, F. A. P.; IMAIZUMI, H.; PIRES, A. V.; SCOTON, R. A. Substituição do farelo de soja por uréia ou amiréia para vacas em final de lactação. Acta Scientiarum, v. 27, n. 2, p. 277-286, 2005.

10 OLIVEIRA, A. S.; VALADARES, R. F. D.; VALADARES FILHO, S. C.; CECON, P. R.; OLIVEIRA, G. A.; SILVA, R. M. N.; COSTA, M. A. L. Consumo, digestibilidade aparente, produção e composição do leite de vacas 
alimentadas com quatro níveis de compostos nitrogenados não-protéicos. Revista Brasileira de Zootecnia, v. 30, n. 4, p. 1358-1366, 2001.

11 SILVA, R. M. N.; VALADARES, R. F. D.; VALADARES FILHO, S. C.; CECON, P. R.; CAMPOS, J. M. S.; OLIVEIRA, G. A.; OLIVEIRA, A. S. Uréia para vacas em lactação. 1. Consumo, digestibilidade, produção e composição do leite. Revista Brasileira de Zootecnia, v. 30, n. 5, p. 1639-1649, 2001.

12 REYNAL, S. M.; BRODERICK, G. A. Effect of dietary level of rumen-degraded protein on production and nitrogen metabolism in lactating dairy cows. Journal of Dairy Science, v. 88, n. 11, p. 4045-4064, 2005.

13 BATEMAN, H. G.; SPAIN, J. N.; KERLEY, M. S.; BELYEA, R. L.; MARSHALL, R. T. Evaluation of ruminally protected methionine and lysine or blood meal and fish meal as protein sources for lactating Holsteins. Journal of Dairy Science, v. 82, n. 10, p. 2115-2120, 1999.

14 COULON, J. B.; HURTAUD, C.; REMOND, B.; VERITE, R. Factors contributing to variation in the proportion of casein in cows' milk true protein: a review of recent INRA experiments. Journal of Dairy Research, v. 65, n. 3, p. 375-387, 1998.

15 CUNHA, C. R.; SPADOTI, L. M.; ZACARCHENCO, P. B.; VIOTTO, W. H. Efeito do fator de concentração do retentado na composição e proteólise de queijo Minas Frescal de baixo teor de gordura fabricado por ultrafiltração. Ciência e Tecnologia de Alimentos, v. 22, n. 1, p. 82-87, 2002. 